\title{
Characterization of a vacuolar sucrose transporter, HbSUT5, from Hevea brasiliensis: involvement in latex production through regulation of intracellular sucrose transport in the bark and laticifers
}

\author{
Xiangyu Long ${ }^{1 * \dagger}$, Heping Li $i^{1,2,3 \dagger}$, Jianghua Yang ${ }^{1}$, Lusheng Xin ${ }^{1,2}$, Yongjun Fang ${ }^{1}$, Bin He ${ }^{1,2}$, Debao Huang ${ }^{1,2}$ and \\ Chaorong Tang ${ }^{1,2^{*}}$
}

\begin{abstract}
Background: Sucrose (Suc), as the precursor molecule for rubber biosynthesis in Hevea brasiliensis, is transported via phloem-mediated long-distance transport from leaves to laticifers in trunk bark, where latex (cytoplasm of laticifers) is tapped for rubber. In our previous report, six Suc transporter (SUT) genes have been cloned in Hevea tree, among which HbSUT3 is verified to play an active role in Suc loading to the laticifers. In this study, another latex-abundant SUT isoform, HbSUT5, with expressions only inferior to HbSUT3 was characterized especially for its roles in latex production.

Results: Both phylogenetic analysis and subcellular localization identify HbSUT5 as a tonoplast-localized SUT protein under the SUT4-clade (=type III). Suc uptake assay in baker's yeast reveals HbSUT5 to be a typical Suc- $\mathrm{H}^{+}$ symporter, but its high affinity for Suc $(\mathrm{Km}=2.03 \mathrm{mM}$ at $\mathrm{pH}$ 5.5) and the similar efficiency in transporting both Suc and maltose making it a peculiar SUT under the SUT4-clade. At the transcript level, HbSUT5 is abundantly and preferentially expressed in Hevea barks. The transcripts of HbSUT5 are conspicuously decreased both in Hevea latex and bark by two yield-stimulating treatments of tapping and ethephon, the patterns of which are contrary to HbSUT3. Under the ethephon treatment, the Suc level in latex cytosol decreases significantly, but that in latex lutoids (polydispersed vacuoles) changes little, suggesting a role of the decreased HbSUT5 expression in Suc compartmentalization in the lutoids and thus enhancing the Suc sink strength in laticifers.
\end{abstract}

Conclusions: Our findings provide insights into the roles of a vacuolar sucrose transporter, HbSUT5, in Suc exchange between lutoids and cytosol in rubber-producing laticifers.

Keywords: Sucrose transporter, Laticifer, Vacuole, Latex production, Rubber tree

\footnotetext{
*Correspondence: yuxianglong006@163.com; chaorongtang@126.com

${ }^{+}$Xiangyu Long and Heping Li contributed equally to this work.

'Key Laboratory of Biology and Genetic Resources of Rubber Tree, Ministry of Agriculture, Rubber Research Institute, Chinese Academy of Tropical Agricultural Sciences, Haikou 571101, Hainan, China

Full list of author information is available at the end of the article
}

(c) The Author(s). 2019 Open Access This article is distributed under the terms of the Creative Commons Attribution 4.0 International License (http://creativecommons.org/licenses/by/4.0/), which permits unrestricted use, distribution, and reproduction in any medium, provided you give appropriate credit to the original author(s) and the source, provide a link to the Creative Commons license, and indicate if changes were made. The Creative Commons Public Domain Dedication waiver (http://creativecommons.org/publicdomain/zero/1.0/) applies to the data made available in this article, unless otherwise stated. 


\section{Background}

Natural rubber (cis-polyisoprene) is a kind of crucial industrial raw material, and its commercial source is exclusively from a tropical tree species, Hevea brasiliensis (para rubber tree). As in all plants, photosynthetic carbohydrates produced in the leaves are essential energy sources for growth and metabolism of Hevea trees. Sucrose (Suc) is the major transport form of photosynthetic carbohydrates from the leaves to peripheral tissues [1], and also serves as a substrate for rubber biosynthesis in the cytoplasm (latex) of specialized phloem rubber-producing laticifers $[2,3]$. Translocation of Suc to various sinks is mediated by Suc transporters (SUTs) [4-7], which are membrane proteins with twelve transmembrane spanning domains $[8,9]$. SUTs are normally divided into five clades (SUT1 to 5) or three types (I to III; type I = SUT1 clade, type II = SUT2, SUT3 and SUT5 clades, type III = SUT4 clade), by specific physiological characteristics and functions [6, 7, 10-13].

In regularly exploited rubber trees, the laticifers in trunk bark represent a major Suc sink, and Suc concentration in latex is positively correlated with rubber yield under some circumstances [14-18]. The vital role of a SUT1-clade member, HbSUT3 (synonym: HbSUT1B) in Suc loading to laticifers and consequentially in rubber productivity, have been previously demonstrated $[19,20]$. To increase our understanding of the regulatory networks of Suc loading, transport and storage in rubber-producing laticifers, it is necessary to characterize the other HbSUTs expressed in these cells. In the latex of Hevea trees, the expression of a SUT4-clade member, HbSUT5, was only lower than HbSUT3 among the six SUT genes [19, 21]. Most plant species seem to have only one SUT4 member, and their physiological roles have attracted much attention in recent years. Interestingly, most of the SUT4 clade members characterized to date have been assigned to the vacuolar membrane (tonoplast), regulating networks of Suc loading, transport and storage in vacuoles [22-26]. In the laticifers of Hevea trees, lutoids, as a polydispersed system of vacuoles, comprise nearly $20 \%$ of the latex volume, and are critical in controlling the duration of latex flow after tapping, thereby influencing latex yield [27]. Lutoids are also thought to function in storage and detoxification, and have lysosomal and osmotic roles. Therefore, characterizing the physiological roles of the potential lutoid membrane-localized SUT member HbSUT5 is of great interest. In the present study, the functions of HbSUT5 were investigated by subcellular localization, in planta expressions under different conditions, and Suc uptake kinetics in baker's yeast, in order to define a possible physiological role in latex production.

\section{Results}

Subcellular identification of HbSUT5

The H. brasiliensis SUT (HbSUT) gene, HbSUT5, was cloned previously [19, 21], but has not been further characterized. HbSUT5 contained a 1497-bp-long ORF that predicted a protein of 498 amino acids with theoretical molecular weight of $54.1 \mathrm{kDa}$ and $\mathrm{pI}$ of 9.39 . Phylogenetic analysis (Fig. 1a) revealed that HbSUT5, together with another Hevea tree SUT, HbSUT4, belongs to SUT4 clade SUTs. As predicted by the method of TMHMM (http://www.cbs.dtu.dk/services/TMHMM/) [28], HbSUT5 consists of 12 transmembrane spans, short cytoplasmic $\mathrm{N}$ - and C-terminals, and a short central cytoplasmic loop between transmembrane spans 6 and 7, the characters of which are typical of the SUT4 clade SUT members (Additional file 2: Figure S1) [5]. To further verify the subcellular locations of HbSUT5, the HbSUT5 protein fused with GFP (green fluorescent protein) was transiently expressed in rice protoplasts together the known rice tonoplast intrinsic protein OsTIP1;1 fused with RFP (red fluorescent protein) [29]. The GFP signals overlapped completely with the RFP signals (Figs. 1b-e), indicating that HbSUT5 shares a similar subcellular location with the well-characterized tonoplast protein OsTIP1;1. High-stringency DNA gel blot analysis showed that there are one to three hybridization bands under different restriction analyses, indicating HbSUT5 to be a single or low copy gene in the Hevea genome (Fig. 1f), the results of which has been further verified by our high-quality draft genome of the rubber tree [30].

\section{Functional analysis of HbSUT5 in baker's yeast}

To test whether HbSUT5 has Suc transport activity, assays with baker's yeast cells expressing the HbSUT5 cDNA were performed using radiolabeled ${ }^{14} \mathrm{C}$-Suc. Suc transport into yeast cells expressing the HbSUT5 was found to be nearly linear within the assayed time course (2 to $10 \mathrm{~min}$ ), reaching approximately 13 -fold higher than that of the control yeast harboring the empty vector pDR196 after 10 min (Fig. 2a). These results demonstrated that HbSUT5 encodes a functional Suc transporter.

Suc transport kinetics analysis displayed that the transport activity of HbSUT5 was obviously dependent on the $\mathrm{pH}$ of the buffer solution, showing the highest at $\mathrm{pH}$ around 5.0 but decreasing progressively with the elevation of buffer $\mathrm{pH}$ (Fig. 2b). The Suc affinities of HbSUT5 were measured at $\mathrm{pH} 5.5$ under a Suc substrate range of $0.5-8 \mathrm{mM}$, and the data were used to perform the Michaelis-Menten analysis (Fig. 2c). The Eadie-Hofstee double-reciprocal plots of the data (Fig. 2d) revealed that the estimated $\mathrm{Km}$ was $2.03 \mathrm{mM}$ with a transport rate Vmax of 0.522 Suc $\min ^{-1}\left(10^{8} \text { cells }\right)^{-1}$, suggesting HbSUT5 belongs to a high-affinity/low-capacity (HALC) Suc transporter [31].

The substrate specificity of HbSUT5 was detected with several unlabeled sugars as ${ }^{14} \mathrm{C}$-Suc competitors, including galactose, fructose, inositol, lactose, Suc, maltose and 


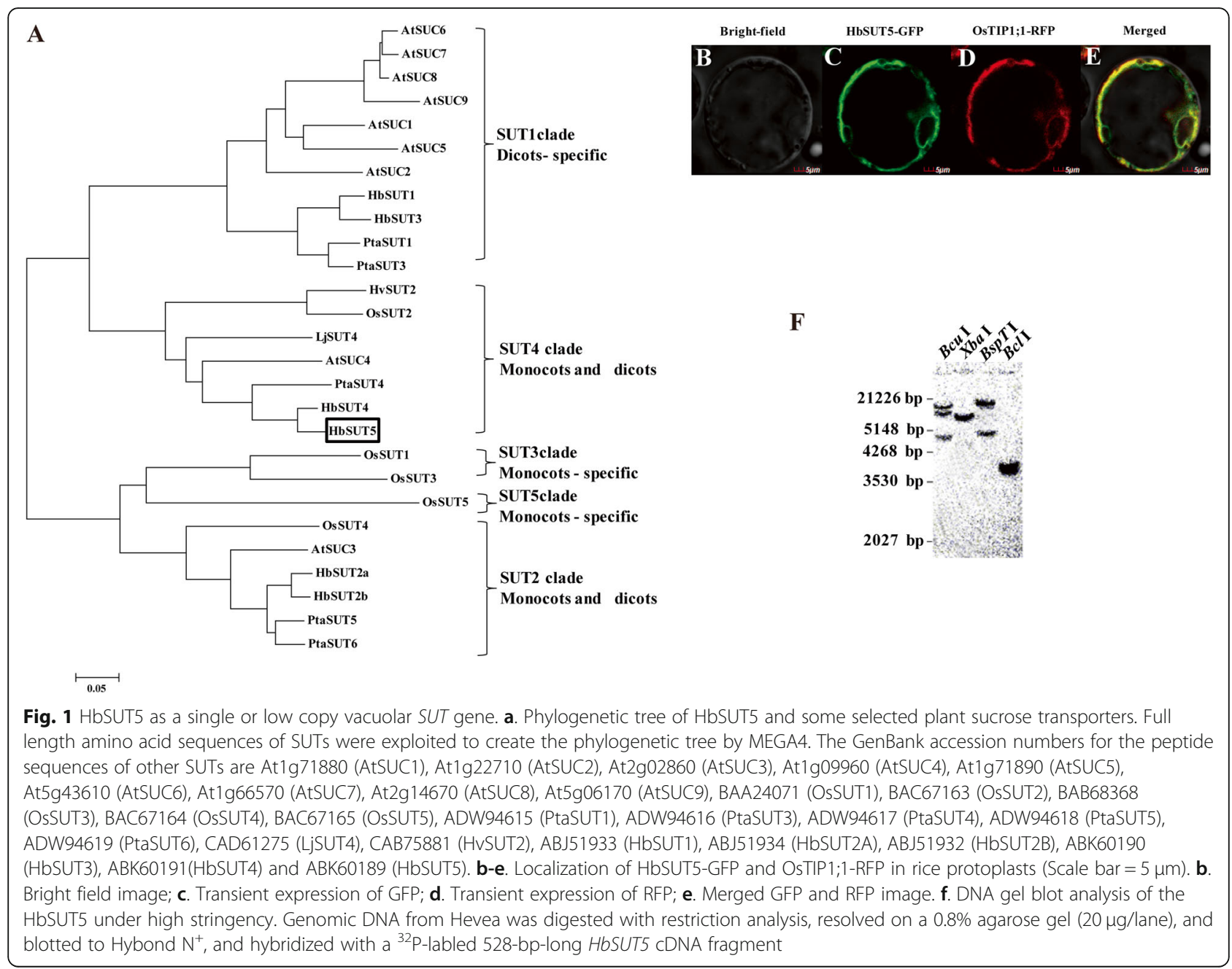

raffinose. The results showed that only Suc and maltose could significantly compete at similar extents with the ${ }^{14} \mathrm{C}$-Suc uptake (Table 1 ), indicating the relative substrate specificity of HbSUT5 in transporting sugars. In addition, three sugars, i.e., fructose, inositol and lactose revealed to stimulate Suc uptake somewhat. Further, Suc transport by HbSUT5 was strongly inhibited by the protonophores of carbonyl cyanide $m$-chlorophenylhydrazone (CCCP) and dinitrophenol (DNP) (Table 1). This result together with the character of $\mathrm{pH}$-dependent Suc transport ability (Fig. 2b) clearly indicated that HbSUT5 was a $\mathrm{H}^{+}$-Suc symporter.

\section{In planta expression patterns of HbSUT5}

As reported previously, among the six HbSUT genes, HbSUT5 is abundantly expressed in the latex, only inferior to HbSUT3, and shows much higher expression than that of the other SUT4-clade SUT gene, HbSUT4 [19]. Besides being an abundant SUT isoform in the latex, HbSUT5 was the predominant isoform in the bark (Fig. 3a), predicting the multifunctional roles of this gene. The transcript abundance of HbSUT5 was then compared by QPCR (quantitative polymerase chain reaction) in five Hevea tissues, including leaf, latex, seed, flower and bark. As shown in Fig. 3b, HbSUT5 was most highly expressed in the bark and seed, followed by the latex and leaf, and the lowest in the flower.

Increased Suc loading to the laticifers is one of the most important mechanisms responsible for ethylene-stimulated latex production [19, 32, 33]. To further investigate the functions of $H b S U T 5$, its expression patterns were analyzed in the latex and bark tissues by QPCR after ethephon (2chloroethylphosponic acid, an ethylene releaser) bark treatment. HbSUT5 expression was significantly down-regulated both in the latex and bark tissues, attaining at $24 \mathrm{~h}$ post treatment about $40 \%$ of its initial level in the latex and $15 \%$ in the bark (Fig. 4a). To further probe the roles of decreased HbSUT5 expression under the ethephon treatment, the Suc contents were examined in latex cytosol (C-serum) and lutoids (B-serum). The results showed that the $\mathrm{C}$-serum Suc was decreased significantly by the treatment, but the Bserum Suc was much less affected, suggesting a function of 

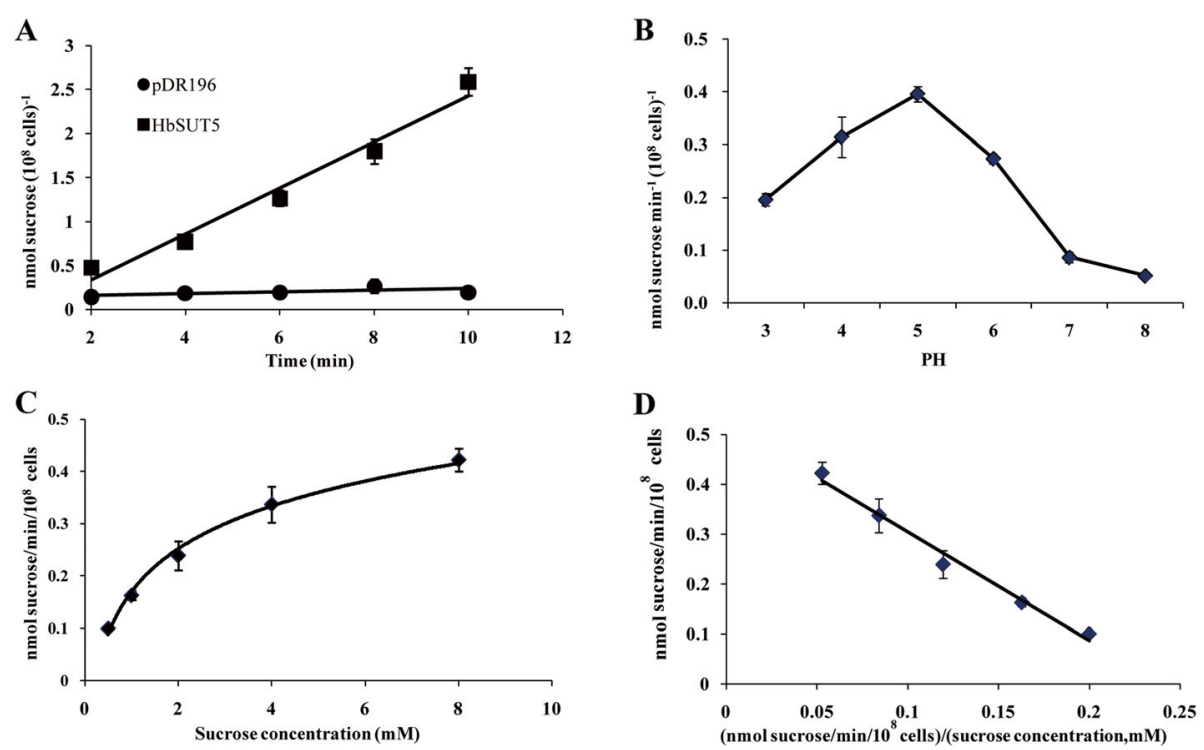

Fig. 2 Characterization of the sucrose transport function of HbSUT5 in baker's yeast Saccharomyces cerevisiae SEY6210. a. Time course of sucrose uptake; $\mathbf{b}$. Effects of pH on sucrose uptake; c. Concentration-dependent uptake; $\mathbf{d}$. An Eadie-Hofstee plot representing the mean rate of uptake as a function of sucrose concentration

the lowered HbSUT5 expression in reducing Suc export from lutoids (Fig. 4b). The tapping of virgin (never tapped before) Hevea trees is an ideal model to identify and characterize latex regeneration-related genes due to the conspicuous stimulating effect of tapping on latex production for the first few tappings $[19,34]$. As shown in Fig. 3c, the expressions of HbSUT5 in the latex markedly depressed with the first four consecutive tappings, reaching less than $4 \%$ of its initial level, and maintaining low levels

Table 1 Effect of competing sugars and inhibitors on sucrose uptake by HbSUT5 expressed in SEY6210 yeast

\begin{tabular}{ll}
\hline Treatment & $\%$ Activity* $^{*}$ \\
\hline Competing sugars & 100 \\
Control & $101 \pm 7.5$ \\
$10 \mathrm{mM}$ Galactose & $121 \pm 9.5^{\mathrm{a}}$ \\
$10 \mathrm{mM}$ Frucose & $130 \pm 15.9^{\mathrm{a}}$ \\
$10 \mathrm{mM}$ Inositol & $132 \pm 6.2^{\mathrm{a}}$ \\
$10 \mathrm{mM}$ Lactose & $42 \pm 2.6^{\mathrm{A}}$ \\
$10 \mathrm{mM}$ Sucrose & $44 \pm 3.4^{\mathrm{A}}$ \\
$10 \mathrm{mM}$ Maltose & $110 \pm 7.0$ \\
$10 \mathrm{mM}$ Raffinose & \\
Inhibitors & 100 \\
Control & $86 \pm 5.5^{\mathrm{a}}$ \\
$50 \mu M$ CCCP & $89 \pm 6.9^{\mathrm{a}}$ \\
\hline $0 \mu \mathrm{M}$ NEM & \\
\hline${ }^{*}$ Analysis of variance (ANOVA) by SAS 6.12, where $P<0.01$ was marked by A, \\
and P<0.05 by a
\end{tabular}

thereafter, the pattern of which correlates negatively with the conspicuous increase in latex yield with the tappings [19]. Bark wounding that stimulates latex production [35] was also found to decrease HbSUT5 expression (Fig. 3d), reaching the lowest level at $24 \mathrm{~h}$ after treatment. The decreased HbSUT5 expression in the latex by tapping was hypothesized to function in a similar mechanism as it did under the ethephon treatment.

\section{Characterization of the HbSUT5 promoter}

To explore the transcriptional characters of HbSUT5, its putative promoter sequence of about 1.5-kb-long genomic sequence upstream from its start codon (GenBank: KU529197) [36] was characterized by in-silico analysis and heterogeneous transient expression. As revealed by the NNPP (neural network promoter prediction) promoter predictor (http://www.fruitfly.org/seq_tools/promoter.html), this sequence contained a high score (0.99) transcription promoter with a putative transcriptional start site (marked as $\mathrm{C}_{+1}$ ) located $342 \mathrm{bp}$ upstream of the start codon (ATG) (Fig. 5a). The PLACE (plant cis-acting regulatory DNA elements) software (http://www.dna.affrc. go.jp/PLACE/) was then used to analyze the putative cisacting elements harbored by the promoter. A total of 54 distinct cis-regulatory elements were predicted, many of which are implicated in multiple biological processes, including stress and hormone responses, signaling pathways, and tissue-, organ- or metabolism-specific expressions (Fig. 5a; Additional file 1: Table S1). The harboring of multiple minimal elements such as four TATA box and 

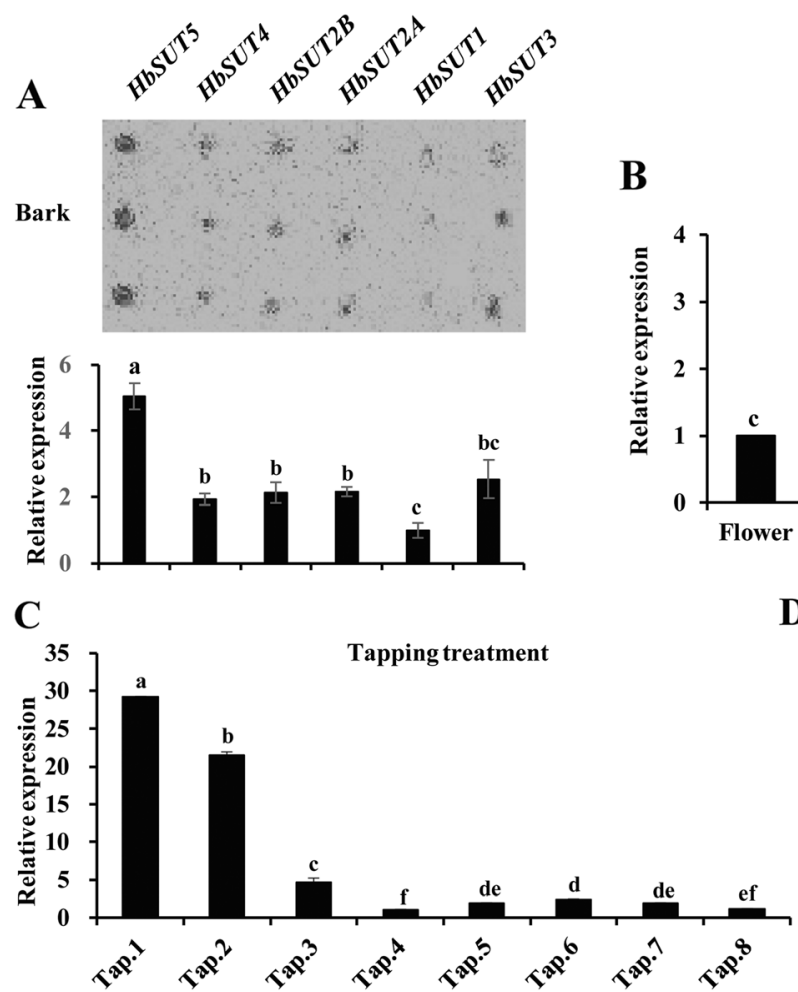

B

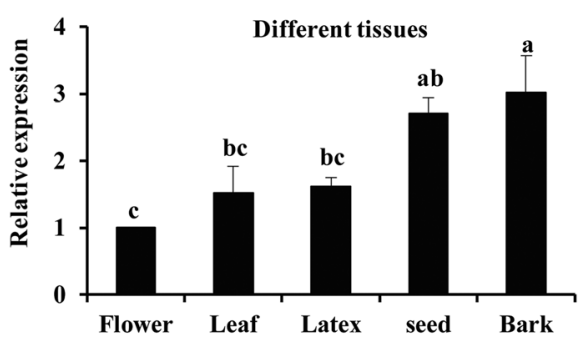

D

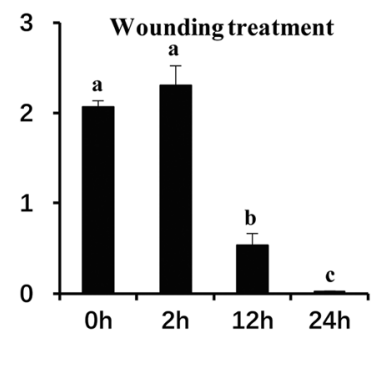

Fig. 3 Expressional characterization of HbSUT5. a, b. Expression of HbSUTs in different Hevea tissues. a. Expression comparison of different HbSUTs in bark was measured by reverse Northern blot analysis; The relative transcript levels were obtained by scanning the intensity of reverse Northern blots. b. Tissue-specific expression patterns of HbSUT5 were measured by QPCR. c, d. Expression of HbSUT5 in response to tapping and wounding treatments by QPCR. Effect of tapping (1st to 8th) (c) and wounding (0 to $24 \mathrm{~h}$ ) (d) treatments on HbSUT5 expression was conducted in mature virgin rubber trees. (Statistical analysis: significant difference, $P<0.01$, marked by different lowercase)

21 CAAT box motifs suggested its capability to initiate accurate basal transcription in most plant species. Experimentally, its promoter activity was confirmed by the transient promoter expression analysis, which revealed a strong GFP fluorescence in tobacco leaf protoplasts transfected with the GFP expression cassette driven by the putative HbSUT5 promoter (pSUT5-GFP) (Fig. 5b).

It is noteworthy that three classical ethylene-responsive elements (EREs) were predicted in the HbSUT5 promoter, with one $(-785)$ on its sense orientation, and the other
A

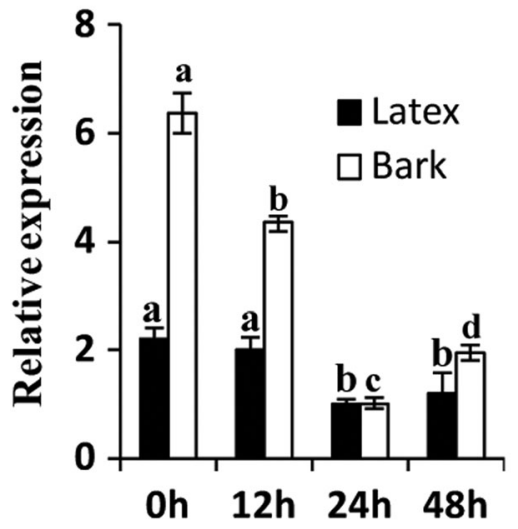

B

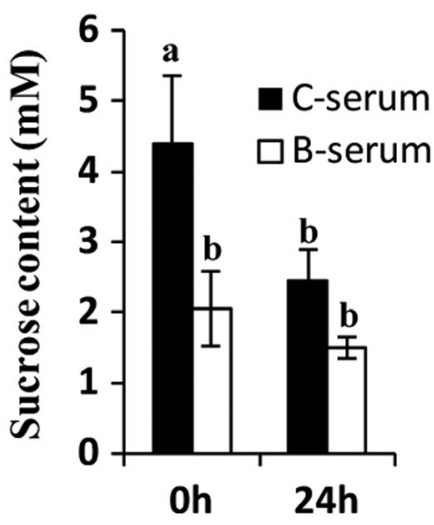

Fig. 4 HbSUT5 influences the sucrose content. a. The expression of HbSUT5 was examined in the latex and bark tissues after 1\% ethephon bark treatment of regularly tapped rubber trees. $\mathbf{b}$. The sucrose content was measured between cytosol (C-serum) and lutoid (B-serum) at $24 \mathrm{~h}$ after $1 \%$ ethephon treatment. (Statistical analysis: significant difference, $\mathrm{P}<0.01$, marked by different lowercase) 


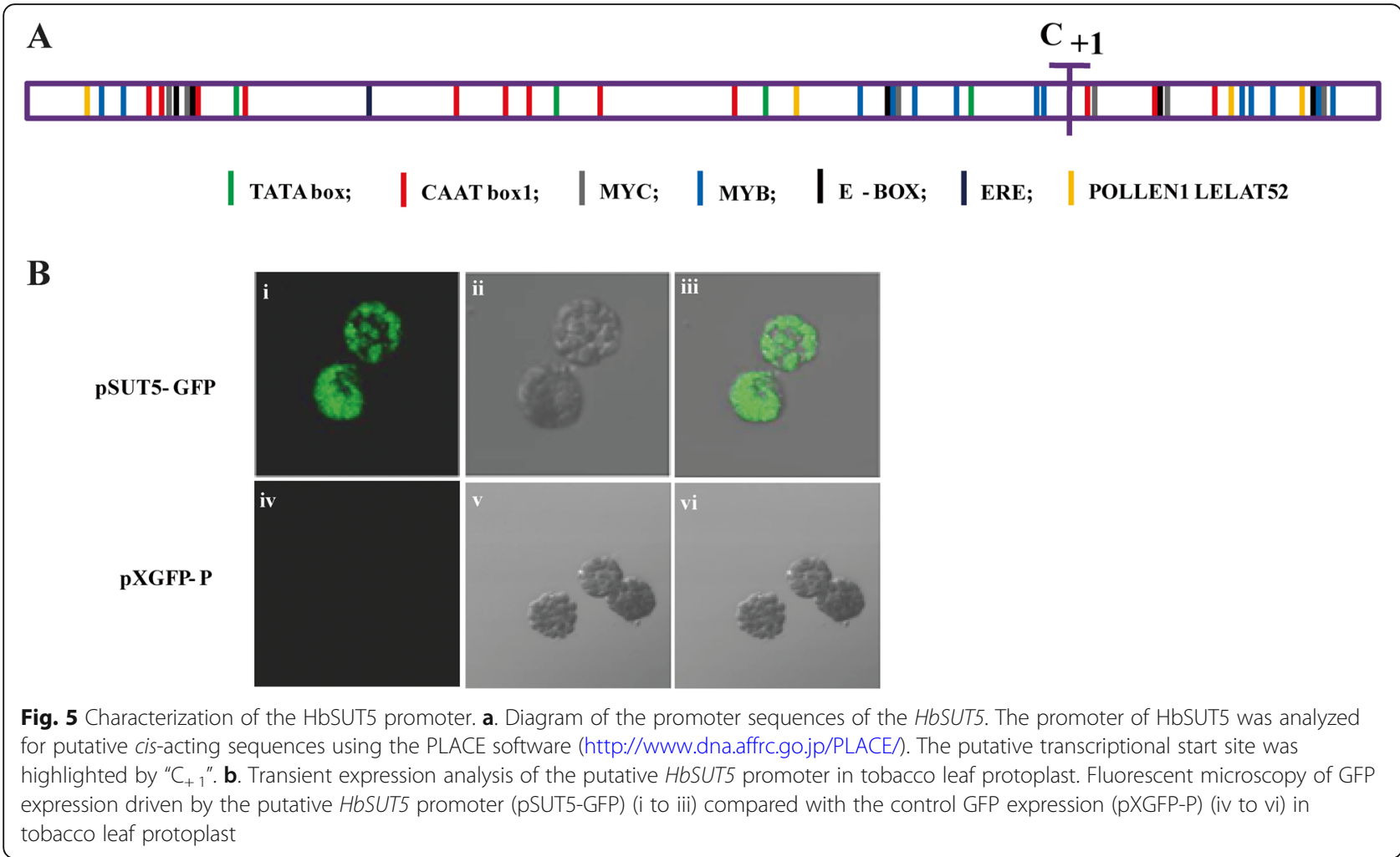

two (- 767 and -327$)$ on its antisense orientation. Besides that, there were 9 cis-acting elements with more than ten locations in the HbSUT5 promoter, among which were those involved in dehydration response (MYB (myeloblastosis) and MYC (myelocytomatosis) recognition sites) [37, 38], tissue- or organ-specific expression (E-Box "CANNTG", POLLEN1 element "AGAAA" and tetranucleotide "YACT") [39, 40, 41], overall expression activation (CT-rich motif "TCTCTCTCT", GATA-Box and ARR1 recognition site "NGATT") [42-44], and sugar metabolism (DOF core recognition site "AAAG") [45].

\section{Discussion}

In higher plants, transportation, distribution and accumulation of photosynthetic carbohydrate are important and essential biochemical processes for growth and development. The photosynthetic carbon assimilates, mainly in the form of Suc, are distributed through phloem loading, long-distance translocation and unloading to diverse sinks [46]. Suc transporters (SUTs) have been demonstrated to be actively involved in these processes, and thus play an important physiological role in carbohydrate partitioning to regulate all known stages of plant growth and development [47-49].

In this study, a $H$. brasiliensis SUT4-clade (=type III) SUT member, HbSUT5, was functionally characterized by subcellular localization study, Suc-uptake assay (Fig. 2 and Table 1) and a number of in planta expressional analyses under a couple of latex-stimulating treatments (Figs. 3 and 4c, d). The HbSUT5 has 12 transmembrane spanning domains (Additional file 2: Figure S1), showing typical structural characters of the GPH (Glycoside-Pentoside-Hexuronide) cation symporter family within the major facilitator superfamily [9]. Phylogenetic (Fig. 1a) and subcellular localization studies (Figs. 1b-e) further identify HbSUT5 as a tonoplast-localized SUT4-clade SUTs. The SUT4-clade SUTs usually have lower affinity for Suc and belong to low-affinity/high-capacity transporters [23, 50-53]. As revealed by the Suc transport assay (Fig. 2), HbSUT5 is a typical Suc- $\mathrm{H}^{+}$symporter as most other SUT4-clade SUTs [23]. However, HbSUT5 has a high affinity for Suc $(K \mathrm{~m}=2.03 \mathrm{mM}$ at $\mathrm{pH} 5.5)$, the character of which differs from most of the SUT4-clade SUT members in higher plants that catalyze Suc uptake with low affinity [7]. The only other SUT4-clade SUT reported to have high Suc-affinity is from carrot, DcSUT1 [54]. In contrast to the ubiquitous tissue expression of HbSUT5 (Fig. 3a, b), the expression of DcSUT1 is restricted in the green part of carrot plants, functioning in phloem Suc loading [54]. In addition to Suc and maltose, the SUT4-clade SUTs can transport a greater variety of glucosides than the SUT2-clade SUTs, but are more specific than the SUT1-clade SUTs [6]. For example, a SUT4-clade SUT from Lotus japonicus, LjSUT4 has broad substrate specificity for glucosides including Suc, salicin, helicon, maltose, sucralose and both $\alpha$ - and $\beta$ - 
linked synthetic phenyl gucosides [23]. Of the seven mono-, di- or tri-saccharides examined, HbSUT5 efficiently transported only Suc and maltose (Table 1). It remains to be determined whether the substrates of HbSUT5 also include some of the glucosides transported by LjSUT4 and other SUT4-clade SUTs [6]. It is also note worthy that HbSUT5 transports maltose as efficiently as it does for Suc (Table 1), and all other characterized SUTs have been found to transport Suc more efficiently than maltose [6].

In mature plant cells, the central vacuole occupies 80 to $90 \%$ of the cell volume and as a sink for accumulation of ions, sugars and a plethora of other metabolites to regulate cellular pressure, detoxification and ecological interactions [55-57]. In Hevea laticifers, vacuoles appear in a polydispersed lysosomal vacuome, i.e. lutoids with storage functions that account for 10 to $20 \%$ by volume of fresh latex (essentially laticiferous cytoplasm) [58]. In recent years, the tonoplast-localized SUTs have been shown to play a regulative role in transporting Suc from the vacuole lumen to the cytoplasm, and function in multiple aspects of plant growth and development [23, 24, 59]. In Lotus japonicus, LjSUT4 is mainly expressed in roots and nodules, and its expression correlates positively with the process of nodulation [26, 59, 60]. In Arabidopsis, AtSUT4 shows higher levels of expression in sink tissues, and functions in sucrose-induced inhibition of seed germination [61]. Using RNA interference (RNAi) in Populus, PtaSUT4 reveals to modulate both Suc export and its utilization in lateral and terminal sinks, and plays an important role in regulating wholeplant water relations, water stress response, and photosynthesis [25, 52]. Inhibition of StSUT4 expression by RNAi leads to increased tuber yield and early flowering in transgenic potato plants, and its expression was also induced by gibberellin and ethephon [62].

In Hevea tree, latex regeneration in laticifers exploits Suc as the precursor molecule for rubber biosynthesis, which represents a high-carbon cost activity [58]. The efficiency of Suc uptake and catabolism in the laticifers is thus crucial for rubber productivity [14,35]. It is now clear that these processes are controlled mainly by a Suc transporter, HbSUT3 [19], and a neutral/alkaline invertase, HbNIN2 [63], respectively. Tapping has a stimulating effect on latex production in virgin rubber trees, the latex yield of which increases conspicuously during the first 7 to 10 tappings [19]. The expressions of both HbSUT3 [19] and HbNIN2 [63] are markedly upregulated by tapping in the latex, indicating an enhanced Suc uptake and catabolism that contributes to latex regeneration. In contrast, the expressions of the tonoplast HbSUT5 in the latex decreased rapidly during the first four tappings, and then retained a low level thereafter (Fig. 3c). We hypothesize that the depression of HbSUT5 expression contributes to tapping-stimulated latex production from two aspects. First, down-regulation of HbSUT5 expression may result in decreased Suc exporting from lutoids into cytosol, and thus enhance further the (Suc) sink strength already stimulated by the activated Suc catabolism in the latex. Second, tapping enhanced Suc compartmentalization in the lutoids, which may benefit the integrity of lutoids and thus the duration of latex flow [27]. In regularly tapped Hevea trees, ethephon bark treatment increases latex production although to a lesser extent compared with the effect of tapping on virgin rubber trees [58]. HbSUT5 expression was downregulated by the ethephon treatment, although not as conspicuous as the tapping treatment (Fig. 3e), which may contribute to latex production in a similar mechanism. This hypothesis is evidenced by examining the Suc levels in latex and its cytosol and lutoids under the ethephon treatment. The marked decrease in the Suc levels both in latex [19] and its cytosol (Fig. 4b) highlights the insignificant change in lutoids Suc. The lowered HbSUT5 expression may function in reducing Suc export from the lutoids. Interestingly, expression of HbSUT5, the trunk bark-dominant SUT isoform (Figs. $3 \mathrm{a}$ and $\mathrm{b}$ ), was also significantly down-regulated by the ethephon treatment in the trunk bark. It remains to be determined in what ways such a regulation affects the Suc concentrations outside the laticifers, and thus the Suc uptake of laticifers. Analysis of HbSUT5 promoter indicates the presence of multiple cis-acting elements implicated in response to various stresses (Fig. 5a). It is remarkable that the HbSUT5 promoter harbors more than ten locations of dehydration-responsive cis-acting elements (Fig. 5a), possibly accounting for the conspicuous effect of tapping on HbSUT5 expression. Tapping, the process of latex harvesting, results in a dehydration stress upon the rubber-producing laticifers, and the expressional responses of various functional genes contribute to harvesting-regulated latex regeneration [64]. Besides that, several ethylene and gibberellin response elements reside in the promoter, indicating the involvement of HbSUT5 in ethylene and gibberellin pathways similar as a potato homolog, StSUT4 [62].

\section{Conclusions}

In this study, we have analyzed another Suc transporter gene, HbSUT5, in Hevea tree. HbSUT5 is a vacuolar Suc transporter that belong to SUT4-clade (=type III) and has high affinity for Suc. HbSUT5 is a bark-dominant SUT isoform, but also abundantly expressed in the latex (cytoplasm of laticifers). Contrary to the latex-dominant isoform, HbSUT3, HbSUT5 expressions are obviously decreased by the tapping and ethephon treatments, indicating a negative response to two ways of yield stimulation. Combining the results of Suc content in latex and 
its cytosol and lutoids (polydisperse vacuoles), HbSUT5 is thought to function in Suc exchange between lutoids and cytosol in laticifers, and thus, together with HbSUT3 influences rubber yield formation in Hevea.

\section{Methods}

\section{Plant materials}

Reyan7-33-97 (synonym: CATAS7-33-97 or RY7-3397) rubber trees (H. brasiliensis) were Hevea cultivars in Hainan Province, and provided by the experimental plantation of CATAS (Chinese Academy of Tropical Agricultural Sciences, Danzhou, Hainan, China). Selected trees were tapped under a $\mathrm{S} / 2 \mathrm{~d} / 3$ system (a half spiral pattern, every three days). Five tissues, flower, leaf, latex, seed and bark, were collected for RNA extraction from Reyan7-33-97 with tapping for two years. The same type of trees was also used to treat with ethephon. The 8-year-old mature virgin (never tapped) trees were selected to treat with tapping and wounding.

\section{Ethylene, wounding and tapping treatment}

For ethylene and wounding treatment, four batches of sixty trees were selected to detect the expression pattern of HbSUT5, and every batch had three biological duplications. In ethylene treatment, one batch was treated with $1 \%$ carboxyl methyl cellulose (CMC) as a control, and the other three batches were treated with $1 \%$ ethephon (2-chloroethylphosponic acid, an ethylene releaser) in $1 \% \mathrm{CMC}$ at 12,24 and $48 \mathrm{~h}$ before tapping. For the wounding treatment, three batches were wounded with pushpin at 2, 12 and 24h before tapping, and the fourth batch was unwounded as the control. According to tapping treatment, fifteen virgin trees were divided into three biological duplications to tap for the first eight tapping. All treated trees were tapped at the same time, and the latex and bark were collected for RNA isolation. The details for ethylene, wounding and tapping treatments and sample collection were as described previously [19]. Besides that, the sucrose content was also measured in latex including cytosol (C-serum) and lutoid (B-serum) after ethephon treatment, using the anthrone method [19].

\section{RNA isolation, CDNA synthesis and QCR}

Total RNA was extracted and treated with DNase I (TaKaRa, China), and examined to concentration and quality by NanoDrop 2000 (Thermo, USA) as described previously [65]. The PrimeScript ${ }^{\text {mi }}$ II 1 st Strand cDNA Synthesis Kit (TaKaRa, China) were used to cDNA systhesis following the manufacturer's protocol. The primer pairs of HbSUT5 (5'-AGTTGCTGGATAAGCTAGAGA-3' and 5'-CGGTGGTCTAGCCCTG-3') were used to analyze the expression patterns, and YLS8 (mitosis protein) as the internal control gene for normalization [66]. The QPCR was operated by CFX96 Touch Real-Time PCR (Bio-Rad, USA), using the SYBR ${ }^{\circ}$ Premix Ex Taq ${ }^{\mathrm{Ta}}$ II (Perfect Real Time) (TaKaRa, China). The PCR reaction system, procedures and data analysis were to follow as the previous research [19].

\section{Southern and reverse northern blot}

Genomic DNA of Reyan7-33-97 was extracted from mature leaves using the CTAB DNA extraction method. One pair of primers (the sense primer: $5^{\prime}$-AACAAAGA AACAGTTGCTGGATAAG-3' and the reverse primer: 5'-CCTGAGTCATGTTATTAGCCAC-3') was designed based on the cDNA and genomic sequences of HbSUT5, and used to amplify an intron-free fragment of 530-bp long that contains no enzyme cutting sites of $B c u \mathrm{I}, \mathrm{Xba}$ I, $B s p T$ I and $B c l$ I. The amplified fragment was digoxigenin-labeled with the Random Primer DNA Labeling Kit (TaKaRa, China), and used as the probe in subsequent Southern blot analysis. The $10 \mu \mathrm{g}$ genomic DNA was digested by $B c u$ I, Xba I, BspT I and $B c l$ I overnight. The digested product was separated on $0.8 \%$ agarose gel and transferred onto a Hybond-N+ membrane (Amersham Pharmacia, USA). And the protocols of Southern blot analysis were performed according to the detailed instructions [67]. The Reverse Northern blot assays were performed to analyze the relative transcript abundance of the six HbSUT genes in bark as described previously [19].

\section{Subcellular localization}

For subcellular localization analysis, the HbSUT5 was sub-cloned with $B s a$ I site into the pBWA(v)HS-gfp vector to produce HbSUT5-GFP fusions. The gene encoding a known tonoplast intrinsic protein, OsTIP1;1, was sub-cloned with $B s a$ I site into pBWD (LB)-mKATE vector to produce OsTIP1;1-RFP fusions. The specific primer pairs used were $5^{\prime}$-CAGTGGTCTCACAACATG GCAATCCCACAGGCGGA-3' and 5'-CAGTGGTCTC ATACATGGGAGGGCCATGGGCTTCT-3' (HbSUT5) and 5 '-CAGTGGTCTCACAACATGCCGATCCGCAA CATCGC-3' and 5'-CAGTGGTCTCATACAGTAGT CGGTGGTGGGGAGCT-3 (OsTIP1;1). The protoplasts from leaves which rice seedlings had been cultured at $30^{\circ} \mathrm{C}$ in darkness after germination for 7 to 15 days were used in transient expression analysis. The two genes with different label signals, HbSUT5 and OsTIP1;1, were co-transformed into protoplasts according to $\mathrm{Yu}$ et al. [68]. The transformed protoplasts were observed with laser scanning confocal microscope (Olympus FV1000, Janpan). The excitation and emission wavelengths were 480 and $510 \mathrm{~nm}$ for GFP, and 588 and $635 \mathrm{~nm}$ for RFP, respectively. 


\section{Suc uptake assay in yeast}

To understand characteristics of Suc transport, the amplified products of HbSUT5 were cut with Sma I and Sal I and cloned into the yeast expression vector pDR196, using the pair primers of $5^{\prime}$-GAGCCCGGGATGGCAATCCCA CAG-3' and 5'-GAACGTCGACTCATGGGAGGGCCA3' (underlined sequences for Sma I and Sal I recognition sites). The constructed vectors were then transformed into the baker's yeast (Saccharomyces cerevisiae) strain SEY6210 for ${ }^{14} \mathrm{C}$-Suc uptake analysis according to the references [19, 69]. The statistical analysis of data was performed by SAS (statistical analysis system).

\section{Analysis of the HbSUT5 promoter}

The HbSUT5 promoter, an approximate $1.5-\mathrm{kb}$ fragment of the 5 '-upstream region of the HbSUT5 gene, had been previously isolated [36], and predicted for its cis-acting elements using the software of PLACE (www.dna.affrc.go. jp/htdocs/PLACE/). The HbSUT5 promoter was amplified using gene-specific primers of 5 '-CGACGGCCCGGGCT GGTA-3' and 5'-TCCCTTCTCCTCGAAAGAAACAC$3^{\prime}$, and inserted into the transient expression vector of pXGFP-P that harbors the reporter gene GFP designed for transient promoter expression analysis [70]. The resulting construct, named as pSUT5-GFP, was transformed into tobacco protoplast using Agrobacterium-mediated approach, and the GFP fluorescence signal was scanned and detected after transformation for $24 \mathrm{~h}$ by a confocal laser scanning microscope (Olympus FV1000, Janpan). The details for the preparation of tobacco protoplast, Agrobacterium-mediated transformation and fluorescence signal scanning, were as described previously $[71,72]$.

\section{Supplementary information}

Supplementary information accompanies this paper at https://doi.org/10. 1186/s12870-019-2209-9

Additional file 1: Table S1. Putative cis-regulatory elements of the HbSUT5 promoter predicted by using the PLACE software

Additional file 2: Figure S1. Prediction of the transmembrane spans for HbSUT5. The prediction was performed using the method of TMHMM (Krogh et al., 2001)

\section{Abbreviations}

CCCP: Protonophores of Carbonyl Cyanide m-Chlorophenylhydrazone; CMC: Carboxyl Methyl Cellulose; DNP: Dinitrophenol; EREs: Ethylene Responsive Elements; GFP: Green Fluorescent Protein; GPH: GlycosidePentoside-Hexuronide; HALC: High-Affinity/Low-Capacity; HbNIN2: Neutral/ alkaline invertase; MYB: Myeloblastosis; MYC: Myelocytomatosis; NNPP: Neural Network Promoter Prediction; ORF: Open Reading Frame; PLACE: Plant cisacting regulatory DNA elements; QPCR: Quantitative Polymerase Chain Reaction; RFP: Red Fluorescent Protein; RNAi: RNA interference; Suc: Sucrose; SUT: Suc Transporter; TIP: Tonoplast Intrinsic Protein

\section{Acknowledgements}

We thank Dr. Yunxia Qin for valuable discussion and suggestions about this study. We also thank Dr. Xiaohu Xiao and Yacheng Huang for their technical assistance.

\section{Authors' contributions}

CRT and XYL conceived the study, and designed the experiments. HPL, JHY, LSX, YJF, BH and DBH executed the experimental work and performed data analysis. CRT and XYL wrote the manuscript. All authors read, edited, and approved the final manuscript.

\section{Funding}

This research was supported by the Natural Science Foundation of Hainan Province (NO. 2017CXTD019), the National Natural Science Foundation of China (NOs. 31825007, 31770709), the Central Public-interest Scientific Institution Basal Research Fund for Innovative Research Team Program of Chinese Academy of Tropical Agricultural Sciences (NO. 17CXTD-28), the Central Public-interest Scientific Institution Basal Research Fund for Chinese Academy of Tropical Agricultural Sciences (Nos. 1630022018019, 1630022017003, 1630022014005) and the National Key R\&D Program of China (2018YFD1000502). The funding organizations payed the costs for this research (experimental costs and publication fees) but not involved in the design of the study and collection, analysis, and interpretation of data and in writing the manuscript.

\section{Availability of data and materials}

All data generated or analyzed during this study are included in this published article and its supplementary information files. The authors are pleased to share the data upon request.

\section{Ethics approval and consent to participate}

Our research dose not used transgenic technology, and all materials used were supplied from the experimental plantation of CATAS (Chinese Academy of Tropical Agricultural Sciences, Danzhou, Hainan, China).

\section{Consent for publication}

Not applicable.

\section{Competing interests}

The authors declare that they have no competing interests.

\section{Author details}

'Key Laboratory of Biology and Genetic Resources of Rubber Tree, Ministry of Agriculture, Rubber Research Institute, Chinese Academy of Tropical Agricultural Sciences, Haikou 571101, Hainan, China. ${ }^{2}$ College of Tropical Crops, Hainan University, Haikou 570228, Hainan, China. ${ }^{3}$ Subtropical Agriculture Research Institute, Fujian Academy of Agricultural Sciences, Zhangzhou 363005, Fujian, China.

Received: 10 June 2019 Accepted: 18 December 2019

References

1. Williams LE, Lemoine R, Sauer N. Sugar transporters in higher plants--a diversity of roles and complex regulation. Trends Plant Sci. 2000;5(7):283-90.

2. Metcalfe CR. Distribution of latex in the plant kingdom. Econ Bot. 1967;21(2): $115-27$.

3. Lewinsohn TM. The geographical distribution of plant latex. Chemoecology. 1991;2(1):64-8.

4. Lalonde S, Tegeder M, Throne-Holst M, Frommer WB, Patrick JW. Phloem loading and unloading of sugars and amino acids. Plant Cell and Environment. 2003;26(1):37-56.

5. Sauer N. Molecular physiology of higher plant sucrose transporters. FEBS Lett. 2007:581(12):2309-17.

6. Reinders A, Sivitz AB, Ward JM. Evolution of plant sucrose uptake transporters. Front Plant Sci. 2012;3:22.

7. Kühn C, Grof CP. Sucrose transporters of higher plants. Curr Opin Plant Biol. 2010;13(3):287-97.

8. Giaquinta R. Phloem loading of sucrose: $\mathrm{pH}$ dependence and selectivity. Plant Physiol. 1977;59(4):750-5

9. Chang AB, Lin R, Keith Studley W, Tran CV, Saier MH Jr. Phylogeny as a guide to structure and function of membrane transport proteins. Mol Membr Biol. 2004;21(3):171.

10. Riesmeier JW, Willmitzer L, Frommer WB. Evidence for an essential role of the sucrose transporter in phloem loading and assimilate partitioning. EMBO J. 1994;13(1):1-7. 
11. Gottwald JR, Krysan PJ, Young JC, Evert RF, Sussman MR. Genetic evidence for the in planta role of phloem-specific plasma membrane sucrose transporters. Proc Natl Acad Sci U S A. 2000;97(25):13979-84.

12. Sivitz $A B$, Reinders $A$, Ward JM. Arabidopsis sucrose transporter AtSUC1 is important for pollen germination and sucrose-induced anthocyanin accumulation. Plant Physiol. 2008;147(1):92.

13. Slewinski TL, Meeley R, Braun DM. Sucrose transporter1 functions in phloem loading in maize leaves. J Exp Bot. 2009;60(3):881-92.

14. Tupý J. The level and distribution pattern of latex sucrose along the trunk of Hevea brasiliensis Mull. Arg. As affected by the sink region induced by latex tapping. Physiologie Vaegaetale. 1973a;11(1):1-11.

15. Eschbach JM, Tupý J, Lacrotte R. Photosynthate allocation and productivity of latex vessels in Hevea brasiliensis. Biol Plant. 1986;28(5):321-8.

16. Jacob J, Serres E, Prévôt JC, Lacrotte R, Vidal A, Eschbach JM, d'Auzac J. Development of Hevea latex diagnosis. Agritrop. 1988;12:97-115.

17. Silpi U, Chantuma P, Kasemsap P, Thaler P, Thanisawanyangkura S, Lacointe A, Améglio T, Gohet E. Sucrose and metabolism distribution patterns in the latices of three Hevea brasiliensis clones: effects of tapping and stimulation on the tree trunk. Journal of Rubber Research. 2006;9(2):115-31.

18. Silpi U, Lacointe A, Kasempsap P, Thanysawanyangkura S, Chantuma P, Gohet E, Musigamart N, Clément A, Améglio T, Thaler P. Carbohydrate reserves as a competing sink: evidence from tapping rubber trees. Tree Physiol. 2007;27(6):881

19. Tang C, Huang D, Yang J, Liu S, Sakr S, Li H, Zhou Y, Qin Y. The sucrose transporter HbSUT3 plays an active role in sucrose loading to laticifer and rubber productivity in exploited trees of Hevea brasiliensis (Para rubber tree). Plant, Cell and Environment. 2010;33(10):1708-20.

20. Dusotoit-Coucaud A, Kongsawadworakul P, Maurousset L, Viboonjun U, Brunel N, Pujade-Renaud V, Chrestin H, Sakr S. Ethylene stimulation of latex yield depends on the expression of a sucrose transporter (HbSUT1B) in rubber tree (Hevea brasiliensis). Tree Physiol. 2010;30(12):1586-98,

21. Yang J. Molecular cloning and sequence analysis of six sucrose transporter genes from Hevea brasiliensis (Para rubber tree). Chinese Journal of Tropical Crops. 2007

22. Endler A, Meyer S, Schelbert S, Schneider T, Weschke W, Peters SW, Keller F, Baginsky S, Martinoia E, Schmidt UG. Identification of a vacuolar sucrose transporter in barley and Arabidopsis mesophyll cells by a tonoplast proteomic approach. Plant Physiol. 2006;141(1):196-207.

23. Reinders A, Sivitz AB, Starker CG, Gantt JS, Ward JM. Functional analysis of LjSUT4, a vacuolar sucrose transporter from Lotus japonicus. Plant Mol Biol. 2008;68(3):289-99.

24. Schulz A, Beyhl D, Marten I, Wormit A, Neuhaus E, Poschet G, Büttner M, Schneider S, Sauer N, Hedrich R. Proton-driven sucrose symport and antiport are provided by the vacuolar transporters SUC4 and TMT1/2. Plant J. 2011;68(1):129-36

25. Payyavula RS, Tay KH, Tsai CJ, Harding SA. The sucrose transporter family in Populus: the importance of a tonoplast PtaSUT4 to biomass and carbon partitioning. Plant J. 2011;65(5):757-70.

26. Radchuk V, Riewe D, Peukert M, Matros A, Strickert M, Radchuk R, Weier D, Steinbiß H, Sreenivasulu N, Weschke W, Weber H. Down-regulation of the sucrose transporters HvSUT1 and HVSUT2 affects sucrose homeostasis along its delivery path in barley grains. J Exp Bot. 2017;68(16):4595-612.

27. Auzac JD, Chrestin H, Marin B, Lioret C. A plant vacuolar system: the lutoids from Hevea brasiliensis latex. Physiologie Vegetale. 1982;20(2):311-31.

28. Krogh A, Larsson B, von Heijne G, Sonnhammer EL. Predicting transmembrane protein topology with a hidden Markov model: application to complete genomes. J Mol Biol. 2001;305(3):567-80.

29. Sakurai J, Ahamed A, Murai M, Maeshima M, Uemura M. Tissue and cellspecific localization of rice aquaporins and their water transport activities. Plant Cell Physiol. 2008;49(1):30-9.

30. Tang C, Yang M, Fang Y, Luo Y, Gao S, Xiao X, An Z, Zhou B, Zhang B, Tan $X$, et al. The rubber tree genome reveals new insights into rubber production and species adaptation. Nature Plants. 2016;2(6):16073.

31. Delrot S, Bonnemain $\mathrm{JL}$. Involvement of protons as a substrate for the sucrose carrier during phloem loading in Vicia faba leaves. Plant Physiol. 1981;67(3):560-4

32. Lacrotte $\mathrm{R}$, Van $\mathrm{dS} \mathrm{H}$, Chrestin $\mathrm{H}$. Ethylene influence on the use of exogenous sucrose by the laticiferous cell in Hevea brasiliensis: proposition for action mechanism [ethrel, ATPase, rubber, latex, rubber tree]. Physiologie vegetale. 1985.
33. Dusotoit-Coucaud A, Brunel N, Kongsawadworakul P, Viboonjun U, Lacointe A, Julien JL, Chrestin H, Sakr S. Sucrose importation into laticifers of Hevea brasiliensis, in relation to ethylene stimulation of latex production. Ann Bot. 2009:104(4):635-47.

34. Pakianathan S, Boatman S, Taysum D. Particle aggregation following dilution of Hevea latex: a possible mechanism for the closure of latex vessels after tapping. J Rubb Res Inst Malaya. 1966;19:259-71.

35. Tupý J. The regulation of Invertase activity in the latex of Hevea brasiliensis Muell. Arg. The effects of growth regulators, bark wounding, and latex tapping. J Exp Bot. 1973b;24(80):516-24.

36. Xin L, Yang J. An improved promoter-cloning method based on adaptorPCR and its application in rubber tree. Bulletin of Botanical Research. 2012 32(3):296-303.

37. Abe H, Urao T, Ito T, Seki M, Shinozaki K, Yamaguchishinozaki K. Arabidopsis AtMYC2 (bHLH) and AtMYB2 (MYB) function as transcriptional activators in Abscisic acid signaling. Plant Cell. 2003;15(1):63-78

38. Lee $\mathrm{BH}$, Henderson DA, Zhu JK. The Arabidopsis cold-responsive transcriptome and its regulation by ICE1. Plant Cell. 2005;17(11):3155-75.

39. Hartmann U, Sagasser M, Mehrtens F, Stracke R, Weisshaar B. Differential combinatorial interactions of cis-acting elements recognized by R2R3-MYB, $\mathrm{BZIP}$, and $\mathrm{BHLH}$ factors control light-responsive and tissue-specific activation of phenylpropanoid biosynthesis genes. Plant Mol Biol. 2005;57(2):155-71.

40. Bate $\mathrm{N}$, Twell D. Functional architecture of a late pollen promoter: pollenspecific transcription is developmentally regulated by multiple stage-specific and co-dependent activator elements. Plant Mol Biol. 1998;37(5):859-69.

41. Gowik U, Burscheidt J, Akyildiz M, Schlue U, Koczor M, Streubel M, Westhoff $P$. Cis-regulatory elements for mesophyll-specific gene expression in the C4 plant Flaveria trinervia, the promoter of the C4 phosphoenolpyruvate carboxylase gene. Plant Cell. 2004;16(5):1077-90

42. Pauli S, Rothnie HM, Chen G, He X, Hohn T. The cauliflower mosaic virus $35 \mathrm{~S}$ promoter extends into the transcribed region. J Virol. 2004;78(22): $12120-8$.

43. Lam E, Chua NH. ASF-2: a factor that binds to the cauliflower mosaic virus $35 \mathrm{~S}$ promoter and a conserved GATA motif in cab promoters. Plant Cell. 1989;1(12):1147-56.

44. Sakai $\mathrm{H}$, Aoyama T, Oka A. Arabidopsis ARR1 and ARR2 response regulators operate as transcriptional activators. Plant J. 2000;24(6):703-11.

45. Yanagisawa S. Dof1 and Dof2 transcription factors are associated with expression of multiple genes involved in carbon metabolism in maize. Plant J. 2000;21(3):281-8.

46. Matsukura C, Saitoh T, Hirose T, Ohsugi R, Perata P, Yamaguchi J. Sugar uptake and transport in rice embryo. Expression of companion cell-specific sucrose transporter (OsSUT1) induced by sugar and light. Plant Physiol. 2000;124(1):85-93.

47. Milne RJ, Perroux JM, Rae AL, Reinders A, Ward JM, Offler CE, Patrick JW Grof CP. Sucrose transporter localization and function in phloem unloading in developing stems. Plant Physiol. 2017;173(2):1330-41.

48. Leach KA, Tran TM, Slewinski TL, Meeley RB, Braun DM. Sucrose transporter2 contributes to maize growth, development, and crop yield. J Integr Plant Biol. 2017;59:408.

49. Ma QJ, Sun MH, Liu YJ, Lu J, Hu DG, Hao YJ. Molecular cloning and functional characterization of the apple sucrose transporter gene MdSUT2. Plant Physiol Biochem. 2016;109:442-51.

50. Sun A, Dai Y, Zhang X, Li C, Meng K, Xu H, Wei X, Xiao G, Ouwerkerk PB, Wang $M$, Zhu Z. A transgenic study on affecting potato tuber yield by expressing the rice sucrose transporter genes OsSUT5Z and OsSUT2M. J Integr Plant Biol. 2011:53(7):586-95.

51. Frost CJ, Nyamdari B, Tsai CJ, Harding SA. The tonoplast-localized sucrose transporter in Populus (PtaSUT4) regulates whole-plant water relations, responses to water stress, and photosynthesis. PLoS One. 2012;7(8):e44467.

52. Wang TD, Zhang HF, Wu ZC, Li JG, Huang XM, Wang HC. Sugar uptake in the aril of litchi fruit depends on the apoplasmic post-phloem transport and the activity of proton pumps and the putative transporter LCSUT4. Plant aand Cell Physiology. 2015;56(2):377-87.

53. Weise A, Barker L, Kühn C, Lalonde S, Buschmann H, Frommer WB, Ward JM. A new subfamily of sucrose transporters, SUT4, with low affinity/high capacity localized in enucleate sieve elements of plants. Plant Cell. 2000;12(8):1345-55.

54. Shakya R, Sturm A. Characterization of source- and sink-specific sucrose/H+ symporters from carrot. Plant Physiol. 1998;118(4):1473-80.

55. Neuhaus HE. Transport of primary metabolites across the plant vacuolar membrane. FEBS Lett. 2007:581(12):2223-6. 
56. Foresti O, De Marchis F, de Virgilio M, Klein EM, Arcioni S, Bellucci M, Vitale A. Protein domains involved in assembly in the endoplasmic reticulum promote vacuolar delivery when fused to secretory GFP, indicating a protein quality control pathway for degradation in the plant vacuole. Mol Plant. 2008;1 (6):1067-76.

57. Hara-Nishimura I, Hatsugai N. The role of vacuole in plant cell death. Cell Death Differ. 2011;18(8):1298-304.

58. Auzac J, Jacob JL, Prévôt JC, Clément A, Gallois R, Crestin H, Lacote R, Pujade-Renaud V, Gohet E: The regulation of cis-polyisoprene production (natural rubber) from Hevea brasiliensis. In: Asia-Pacific Forum on Science Learning and Teaching: 1997. 17.

59. Schneider S, Hulpke S, Schulz A, Yaron I, Höll J, Imlau A, Schmitt B, Batz S, Wolf S, Hedrich R, Sauer N. Vacuoles release sucrose via tonoplast-localised SUC4-type transporters. Plant Biol. 2012;14(2):325-36.

60. Flemetakis E, Dimou M, Cotzur D, Efrose RC, Aivalakis G, Colebatch G, Udvardi M, Katinakis P. A sucrose transporter, LjSUT4, is up-regulated during Lotus japonicus nodule development. J Exp Bot. 2003;54(388):1789-91.

61. Li Y, Li LL, Fan RC, Peng CC, Sun HL, Zhu SY, Wang XF, Zhang LY, Zhang DP. Arabidopsis sucrose transporter SUT4 interacts with cytochrome b5-2 to regulate seed germination in response to sucrose and glucose. Mol Plant. 2012;5(5):1029-41.

62. Chincinska IA, Liesche J, Krügel U, Michalska J, Geigenberger P, Grimm B, Kühn C. Sucrose transporter StSUT4 from potato affects flowering, tuberization, and shade avoidance response. Plant Physiol. 2008;146(2):515-28.

63. Liu S, Lan J, Zhou B, Qin Y, Zhou Y, Xiao X, Yang J, Gou J, Qi J, Huang Y, Tang C. HbNIN2, a cytosolic alkaline/neutral-invertase, is responsible for sucrose catabolism in rubber-producing laticifers of Hevea brasiliensis (Para rubber tree). The New Phytologist. 2015;206(2):709-25.

64. Duan C, Rio M, Leclercq J, Bonnot F, Oliver G, Montoro P. Gene expression pattern in response to wounding, methyl jasmonate and ethylene in the bark of Hevea brasiliensis. Tree Physiol. 2010;30(10):1349-59.

65. Tang C, Qi J, Li H, Zhang C, Wang Y. A convenient and efficient protocol for isolating high-quality RNA from latex of Hevea brasiliensis (Para rubber tree). J Biochem Biophys Methods. 2007;70(5):749-54.

66. Li H, Qin Y, Xiao X, Tang C. Screening of valid reference genes for real-time RT-PCR data normalization in Hevea brasiliensis and expression validation of a sucrose transporter gene HbSUT3. Plant Sci. 2011;181(2):132-9.

67. Li HP: Study on expression profiles of sucrose treansporter HbSUT5 from Hevea brasiliensis. Master. Hainan University; 2010.

68. Yu H, Jiang W, Liu Q, Zhang H, Piao M, Chen Z, Bian M. Expression pattern and subcellular localization of the ovate protein family in rice. PLoS One. 2015;10(3):e0118966.

69. Reinders A, Ward JM. Functional characterization of the alpha-glucoside transporter Sut $1 p$ from Schizosaccharomyces pombe, the first fungal homologue of plant sucrose transporters. Mol Microbiol. 2001;39(2):445-54.

70. Chen S, Songkumarn P, Liu J, Wang GL. A versatile zero background Tvector system for gene cloning and functional genomics. Plant Physiol. 2009:150(3):1111-21

71. Yang Y, Li R, Qi M. In vivo analysis of plant promoters and transcription factors by agroinfiltration of tobacco leaves. Plant J. 2000;22(6):543-51.

72. Zheng L, Liu G, Meng X, Li Y, Wang Y. A versatile agrobacterium-mediated transient gene expression system for herbaceous plants and trees. Biochem Genet. 2012;50(9-10):761-9.

\section{Publisher's Note}

Springer Nature remains neutral with regard to jurisdictional claims in published maps and institutional affiliations.

Ready to submit your research? Choose BMC and benefit from:
- fast, convenient online submission
- thorough peer review by experienced researchers in your field
- rapid publication on acceptance
- support for research data, including large and complex data types
- gold Open Access which fosters wider collaboration and increased citations
- maximum visibility for your research: over 100M website views per year
At BMC, research is always in progress.
Learn more biomedcentral.com/submissions

